\title{
Cytological and Autoradiographic Study on Ribonucleic Acid Synthesis in Preimplantation Eggs of the Syrian Hamster ${ }^{1}$
}

\author{
Tadashi Utakoji ${ }^{2}$ \\ Section of Cell Biology, Department of Biology, \\ The University of Texas M. D. Anderson Hospital and \\ Tumor Institute at Houston, Houston, Texas, U.S.A.
}

Received March 9, 1968

\section{Introduction}

The ribonucleic acid synthesis in cleaving stage embryos has been studied n some detail in amphibia and in echinoderms. In amphibia, results from zutoradiographic studies (Ficq 1964) with RNA precursors agree with biochemical lata that no ribosomal synthesis takes place in mature oocyte and early cleavage stages (Brown 1964). In echinoderms, Brachet, Decroly, Ficq, and Quertier (1963) reported no phosphate incorporation into RNA nucleotids after a short pulse in early cleavage until the blastula stage. But they observed $\mathrm{H}^{3}$-uridine incorporation into nuclei beginning at the 4-cell stage.

Mintz (1964) reported, in her autoradiographic study on the RNA synthesis with tritium labeled RNA precursors, that RNA synthesis in mouse embryos ?ersisted in all cleaving stages after fertilization. Sensitivity of mouse cleaving zggs to Actinomycin D studied by Thomson and Biggers (1966) also indicates active RNA synthesis in early mammalian embryos. These data suggest that RNA synthesis in cleaving stage embryos of placental animals may be different irom that of the noneutherians.

This paper presents results of some cytological and autoradiographic observations on RNA synthesis in the cleaving-stage embryos of the Syrian ramster. The Syrian hamster was used in this study because of the ease in Jbtaining mating and in inducing artificial superovulation.

\section{Material and methods}

Adult male and female Syrian hamsters (Mesocricetus auratus) were surchased through a local breeder. After the confirmation of a 4-day estrus :ycle, superovulation was induced by injecting serum gonadotropin (Equinex, tyerst Laboratories Inc., New York, N. Y.) according to Greenwald's method

1 Supported in part by Research Grants GB-1867 from National Science Foundation Ind E-286 from American Cancer Society.

2 Present address: Pathology Department, Cancer Institute, Nishi-Sugamo, Toshima:u, Tokyo, Japan. 
(1962). Females so treated were mated with normal males at succeeding estrus.

At certain intervals after mating, ovaries, oviducts and uteri were excised under light general anesthesia. The number of freshly ovulated, hemorrhagic follicles in the ovaries were counted to ascertain the superovulation. The oviduct and the uterus were flushed through the infundibulum caudal to the uterus by a syringe with a fine needle (No. 30 hypodermic) containing approximately $0.5 \mathrm{ml}$ of tissue culture medium. The developing eggs were collected in a watch glass under a dissecting microscope with a capillary pipette, and washed with fresh medium. They were then treated with $0.5 \%$ Pronase (Calbiochem, Los Angeles, California) dissolved in Hanks' solution for 3 to 5 minutes at room temperature to remove the zona pellucida (Mintz 1962). Embryos, free of the zona pellucida, were carefully washed with fresh medium, and 5 to 6 of them were placed on each microscopic slide. A coverslip was placed gently over them. The amount of the medium, which contained the embryos, was carefully controlled because the compression on the embryos depended upon the weight of the coverslip and the capillary action between the coverslip and the slide. The compression should be sufficient to bring most cellular components to single microscopic focus, but should not damage the individual blastomeres.

The flattened whole-mount preparations were rapidly frozen in ethanoldry ice mixture for not less than 5 minutes, and coverslips were flipped off quickly with a sharp scalpel. The slides were immediately (while they were still frozen) fixed in absolute methanol for 10 minutes at room temperature, stained with May-Grünwald-Giemsa solutions, and sealed in Permount. Some slides were also stained with acridine orange (Chroma, $0.25 \mathrm{mg} / \mathrm{ml}$ in $0.1 \mathrm{M}$ acetate buffer, $\mathrm{pH} 5.0$ ) for 15 minutes, washed with several changes of the buffer solution, and observed with the fluorescence microscope.

Incorporation of tritiated uridine ( $\mathrm{H}^{3}-\mathrm{UR}$, specific activities 3.5 and 16.6 $\mathrm{Ci} / \mathrm{mM}$, New England Nuclear Corp., Boston, Massachusetts) by the embryos was performed in vitro for those which were still in oviduct, and in vivo for the later stage embryos which were already in the uterus. $H^{3}-U R$ was diluted to a concentration of $100 \mu \mathrm{Ci} / \mathrm{ml}$ with Hanks' solution and the $\mathrm{pH}$ of the labeling solution was adjusted to approximately 7.6 .

For the $\mathrm{H}^{3}-\mathrm{UR}$ in vitro labeling of fertilized, uncleaved zygotes and early cleaving stage eggs (up to 4-cell stage), the freshly removed oviducts, which contained eggs, were immediately placed in labeling solution under mineral oil (Brinster 1963) and incubated in a $\mathrm{CO}_{2}$ incubator at $38^{\circ} \mathrm{C}$ for 1 hour.

Developing eggs of 5 -cell to blastocyst were labeled in vivo with intrauterine injection of $\mathrm{H}^{3}-\mathrm{UR}$ solution. Females at approximately 60 to 100 hours following mating were lightly anesthesized, laparotomized, and each cornu uteri was ligated at the immediate vicinity of the uterine bifurcation to prevent the leakage of the labeling fluid. The labeling solution was injected 
in each uterine horn, laparotomy was temporarily closed; and the animal was released.

At desired intervals after the introduction of $\mathrm{H}^{\prime}-\mathrm{UR}$ in both in vitro and in vivo labeling experiments, the embryos were flushed out, removed of the zona pellucida with Pronase, squashed and fixed as described before. Autoradiographs were made with Kodak AR 10 stripping film and were developed with Kodak D $19 \mathrm{~b}$ for 3 minutes at $20^{\circ} \mathrm{C}$. The exposure period was 7 to 10 days. Preparations were stained with buffered Giemsa solution.

\section{Results}

\section{Cytological observations}

Three superovulated females were sacrificed with a colchicine pretreatment (intraperitoneal injection, $5 \mathrm{mg} / \mathrm{animal}, 2$ hours before sacrifice) at 24 to 25 hours after mating for cytological study of the first cleavage. In 6 ovaries 160 ovulations were ascertained, and detailed observations were done on MayGrünwald-Giemsa stained, whole-mount squash preparation of 72 zygotes. Of these, various stages of the first cleavage were found as shown in the Table. Relatively large amount of colchicine (Orsini and Pansky 1952) failed to arrest the metaphase of the first cleavage, whereas in the bone marrow of the same individual the metaphase arrest was definitely demonstrated by the large number of c-metaphases and far less frequent anaphase figures.

Two round pronuclei in the zygote were approximately the same size and were stained faintly red except the round or oval heteropycnotic masses which were stained deeply red (Figs. 1 and 11) in May-Grünwald-Giemsa preparations. The average number of these heteropycnotic masses was 6 , ranging from 1 to 18 in each pronucleus. No other structure was found in the pronucleus by light microscopy.

In the prophase of the first cleavage, the chromosomes appeared within each pronucleus. The male and female pronuclei were situated close to each other near the center of the cell (Fig. 2). As prophase proceeded, the chromosomes became increasingly condensed, and at late prophase the relational coiling between the chromatids was clearly visible (Fig. 7).

At prometaphase and metaphase, paternally derived and maternally derived chromosomes were aligned in a single metaphase plate (Figs. 3 and 8). The chromosomes were considerably larger and longer than those in the mitosis of adult tissues. Relational coilings were still visible in the metaphase chromosomes. However, at fully developed metaphase plates immediately prior to anaphase, the chromatid coiling appeared to be disengaged and straightened out. In no case could the chromosomes be recognized and karyotyped.

Anaphase figures were found in 18 zygotes. The chromosomes were elongated and the coiling was not visible in this stage (Figs. 4, 9 and 10).

In developing eggs of the 2-cell stage, sacrificed at approximately 24 hours after mating, the size of the nuclei was smaller than that of the pronucleus 
(Fig. 5). In later stages of 2-cell eggs, more than 25 dark, red heteropycnotic masses could be counted in each nucleus of May-Grünwald-Giemsa stained eggs (Figs. 6 and 12). The remaining part of the nucleus was stained more or less

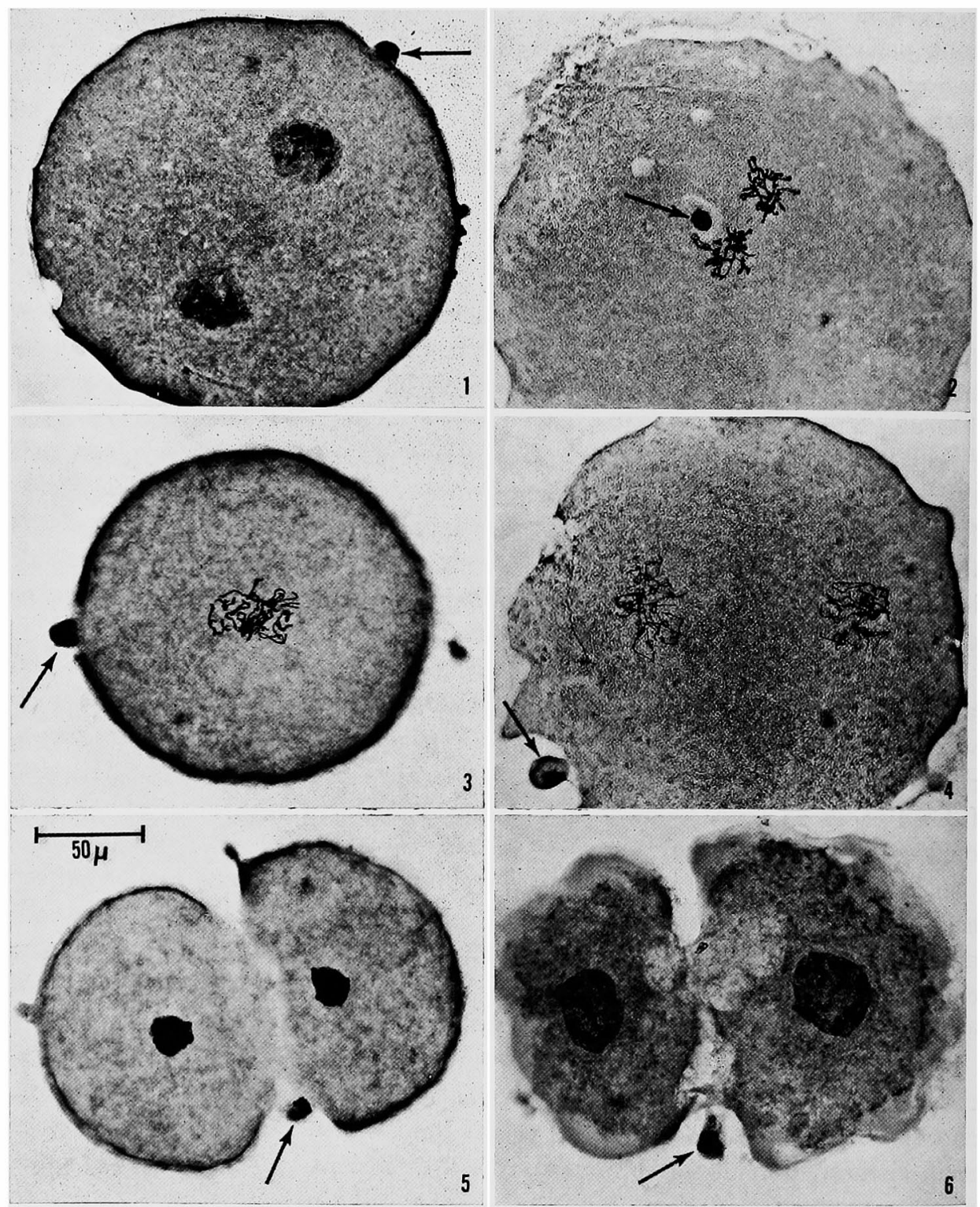

Figs. 1-6. Uncleaved and cleaved zygotes. The scale in Fig. 5 is applicable to all figures in this plate. Arrows indicate polar bodies. Zona pellucida was removed with Pronase. Whole-mount squash preparation, methanol fixed and May-Grünwald-Giemsa stained. Figs. 1-5 were obtained at 24-25 hours after mating and Fig. 6 at 36 hours. 1, pronuclei stage zygote. Note faintly stained pronuclei with densely stained blocks. 2, prophase of the first cleavage. 3 , prometaphase of the first cleavage. 4, anaphase of the first cleavage. 5 , early 2-cell stage zygote. 6, late 2-cell stage zygote. Nuclear structure is different from that in Fig. 5 . 
homogeneously red. The two blastomeres were not completely separated at this time but were attached to each other along a wide area.

When females were sacrificed at approximately 36 hours after mating, all the developing eggs were still in the 2-cell stage. However, the morphology of the nucleus was different from that found in the earlier stage. The nuclei contained, besides numerous heteropycnotic masses, a coarse network of chromatin (Fig. 13). In earlier 2-cell stage eggs stained with May-Grünwald-

Table. Zygotes obtained at 24 to 25 hours after mating (or after the onset of estrus)

\begin{tabular}{l|r}
\hline Pronuclei stage & 23 \\
Prophase & 10 \\
Metaphase & 4 \\
Anaphase & 18 \\
Telophase & 5 \\
Two-cell stage & 12 \\
\hline \multicolumn{1}{c}{ Total } & 72 \\
\hline
\end{tabular}
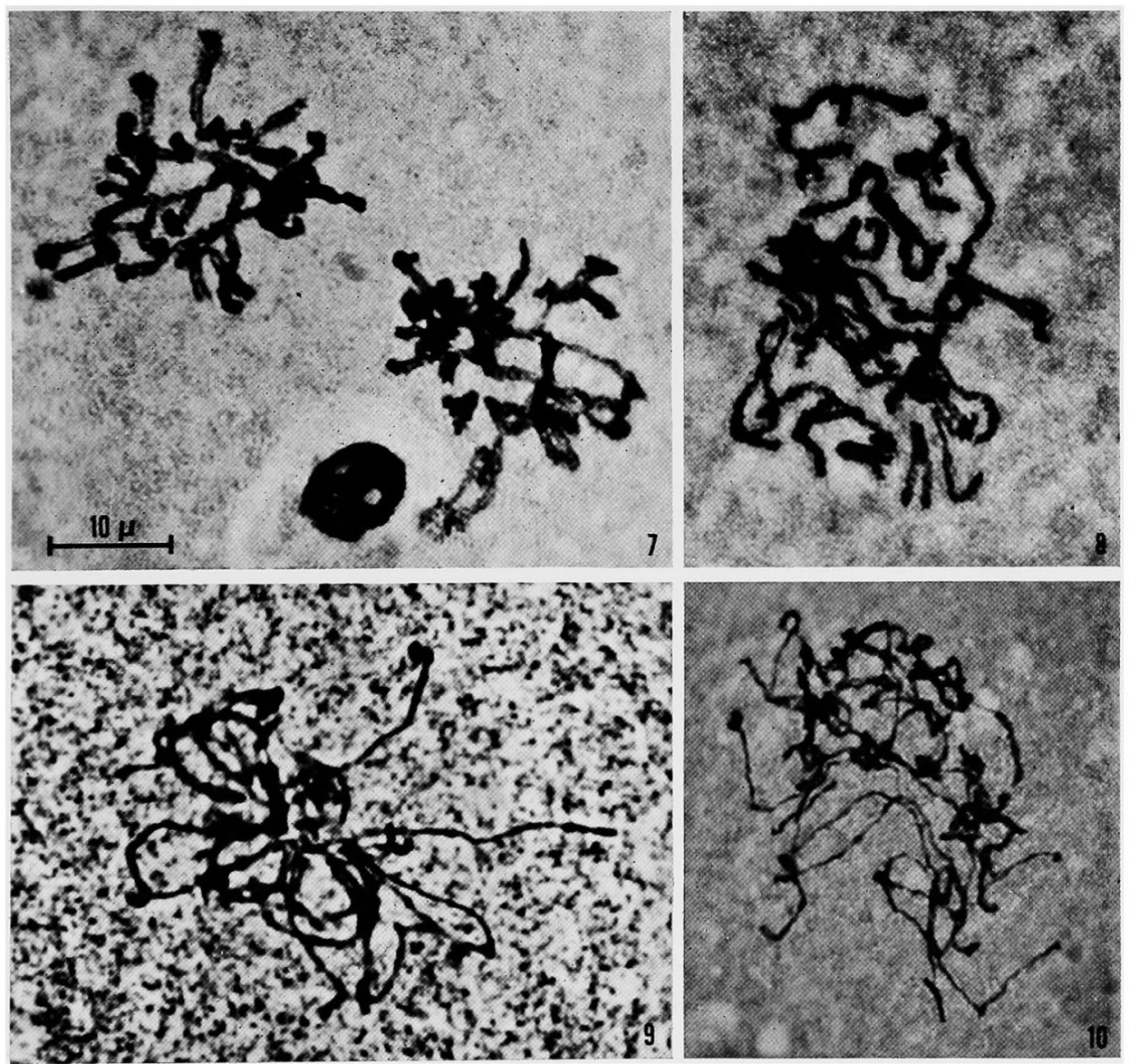

Figs. 7-10. Details of the first cleavage chromosomes. The scale in Fig. 7 is applicable to all figures in this plate. 7, late prophase. The chromosomes belonging to each pronucleus are not mingled. In some chromosomes relational coils between two chromatids are clearly visible. 8, prometaphase. The chromosomes from both pronuclei now form one metaphase plate. Relational coils are still visible. 9 and 10, anaphase. Note extremely long chromosomes. 
Giemsa solution, no blue-stained material (ribonucleoprotein) was detected in the nucleus; but at this stage minute blue-stained material was found to be closely attached to some of the red-stained heteropycnotic masses.

In a female with more than 60 ovulations sacrificed 48 hours after mating, 7 embryos were in the 4-cell stage, one in the 3-cell and 48 in the 2-cell stage. Among 48 eggs in the 2 -cell stage, 5 were in the process of the second cleavage. In the majority of these late 2-cell stage to 4-cell stage embryos, nucleoli adhering to the heteropycnotic masses were observed.

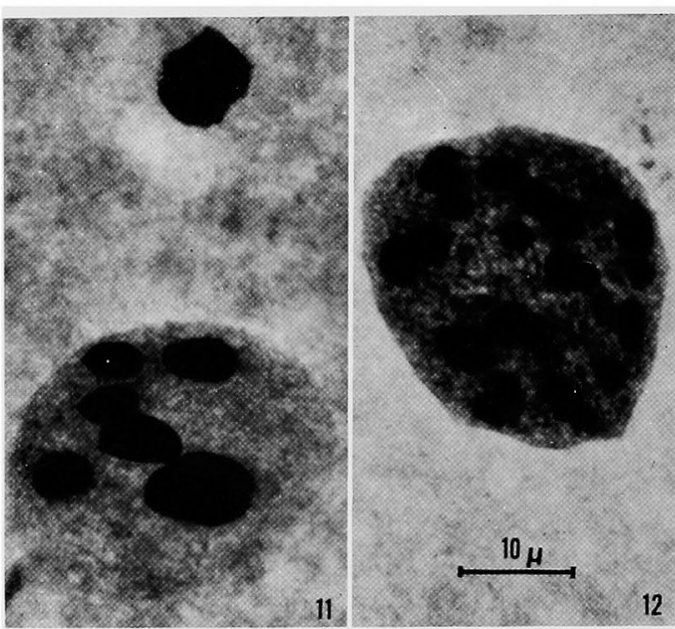

Figs. 11-13. Morphological change in nuclei. The scale in Fig. 12 is applicable to all figures in this plate. Methanol fixation and May-Grünwald-Giemsa staining. 11, pronucleus and polar body of a zygote obtained at 24 hours after mating. 12, early 2-cell stage embryo nucleus, obtained at 24 hours after mating. Note the similar nuclear structure as that of pronucleus. The number of heteropycnotic blocks is larger than that of the pronuclei. There is no blue stained material (ribonucleoprotein) in the nucleus. 13, late 2-cell stage embryo nucleus, obtained at 48 hours after mating. Nuclear structure is considerably different from that of Figs. 11 and 12 . Note coarse chromatin network. Arrows indicate blue stained nucleoli.

At 72 hours after mating, the most advanced embryo contained 14 nuclei but the most retarded one was still in the 2-cell stage. However, 35 of the 55 embryos were in the 7- or 8-cell stages. All embryos recovered from the uterus at this time were still enclosed in a well preserved zona pellucida. The staining behavior of the nuclei was the same as described for the late 2-cell to 4-cell stages.

At 90 hours post-mating and thereafter, blastocysts without zona pellucida were recovered from the uterus. In a blastocyst approximately 100 hours old, 36 nuclei were counted, and the nuclear size differed significantly. Approximately two-thirds of the nuclei of the blastocyst were small and compact, but the rest was three to four times as large as the others in diameter and showed coarse chromatin structure.

During the morula and blastocyst stages, the metaphase chromosomes were 
more condensed, being smaller and shorter than those of the first cleavage division. In several metaphases of the blastocysts, the chromosomes were

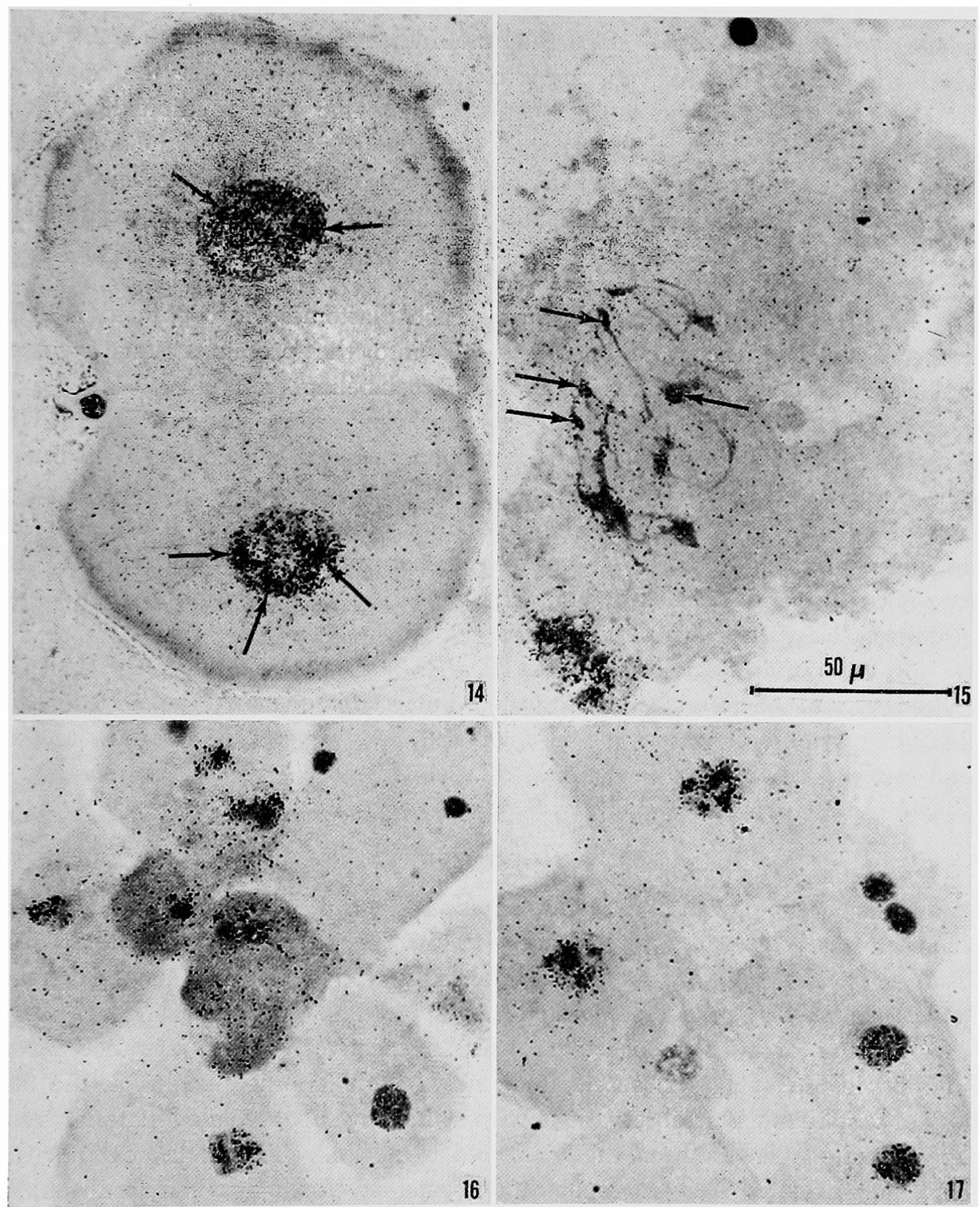

Figs. 14-17. Autoradiographs with $\mathrm{H}^{3}-\mathrm{UR}$. The scale in Fig. 15 is applicable to all figures in this plate. 14 and 15, autoradiographs of late 2-cell stage embryos (48 hours after mating) labeled with $\mathrm{H}^{3}-\mathrm{UR}(100 \mu \mathrm{Ci} / \mathrm{ml}$, specific activity $3.5 \mathrm{Ci} / \mathrm{mM})$ for one hour in vitro. In Fig. 14, nucleoli (arrows) are heavily labeled. Cytoplasmas also have light labeling. Polar body is not labeled. In Fig. 15, one blastomere is in prophase of the second cleavage. Note heavily labeled nucleolar remnants (arrows). Condensing chromosomes are not labeled. 16 and 17, autoradiographs of 8-cell stage embryos (72 hours after mating) labeled with $\mathrm{H}^{3}-\mathrm{UR}(100 \mu \mathrm{Ci} / \mathrm{ml}$, specific activity $16.6 \mathrm{Ci} / \mathrm{mM})$ for one hour in utero. Note heavy label over the nucleoli. The nuclei are moderately labeled, but the nucleus in mitotic process is not labeled. Note different RNA synthetic activities in different blastomeres. 
approximately the same size as those in the adult tissues.

With fluorescence microscope and acridine orange staining of the methanol fixed preparations, the dense bodies in the pronucleus and in the blastomere nucleus of the early 2-cell stage did not indicate that they contained ribonucleoprotein. They did not show orange fluorescence, while the nucleolus and the cytoplasm of the oviduct cell on the same slide exhibited brilliant orange fluorescence. Within the nuclei of the blastomeres of the late 2-cell and 4-cell stages, small bodies with orange fluorescence were found in similar site as the blue stained nucleolus in May-Grünwald-Giemsa stained preparations.

\section{Autoradiographic study of RNA synthesis}

From the 2-cell to morula stages each blastomere incorporated $\mathrm{H}^{3}$-UR into its nucleus. Incorporation of $\mathrm{H}^{3}-\mathrm{UR}$ into the pronuclei stage zygotes could not be demonstrated with our in vitro labeling method.

In developing zygotes of the 2-cell stage, after 1 hour labeling with $\mathrm{H}^{3}-\mathrm{UR}$ in vitro, the most heavily labeled component was the nucleolus. The interphase nuclei were also labeled relatively heavily, but the cytoplasm was only lightly labeled (Fig. 14). The labeling of the cytoplasm of the blastomeres in anaphase and in telophase was not detected above the background level. In one case, several nucleolar remnants were heavily labeled (Fig. 15) in one prophasic blastomere of a 2-cell stage embryo.

In the morula stage labeled with $\mathrm{H}^{3}-\mathrm{UR}$ in utero for 1 hour, the nucleoli exhibited the heaviest label among all cellular components (Figs. 16 and 17), including cytoplasm which was also labeled. However, the amount of the radioactivity among the blastomeres of a single morula varied considerably.

\section{Discussion}

The chronology of the preimplantation stage development of the Syrian hamster has been studied by Graves (1945), Venable (1946), Hamilton and Samuel (1956), and Austin (1956). Their investigations indicated that the first, second, and third cleavages are at approximately 24, 48 and 72 hours after mating (or after the onset of estrus), respectively. The rate of the cell division in later stages is accelerated, and the implantation begins at the 5 th day of gestation. Our observations with artificially superovulated material were approximately the same as those referred to above. This indicates that the artificially ovulated ova are capable of normal development when fertilized, at least in the preimplantation stages.

As early as 1895, Sobotta (1895) observed that in the first cleavage metaphase of the mouse zygote the chromosomes are greatly extended and are many times as long as those of the somatic mitosis. Recently, Austin (1957) reported that the sex chromosomes of the field vole (Microtus agrestis) at the first cleavage metaphase were three times as long as the same chromosomes in the spermatogonial metaphase. Our observation on the Syrian 
hamster zygotes showed the extended chromosomes in more detail. Probably the replacement of the nuclear basic protein from one type to another during the long course of the gametogenesis (Alfert 1950, Das, Kaufmann and Gay 1964) has caused this anomalous behavior of the chromosome condensation at this embryonic stage.

The RNA synthetic activity in uncleaved zygotes could not be demonstrated by our labeling method. Although this apparent absence of RNA synthesis may be due to technical difficulties, the fresh red color of the first cleavage metaphase chromosomes stained with May-Grünwald-Giemsa, and the lack of any appreciable orange fluorescence in pronuclei fluorochromed with acridine orange, do suggest low RNA content of the pronuclei. In living, unfixed pronucleate and cleaving eggs of the rat, Austin and Bishop (1959) also failed to observe any fluorescence in the nucleoli with acridine orange staining.

The rapid change of nuclear structure during the 2-cell stage is remarkable. The change from pronucleus-like structure of the early 2-cell stage nucleus to the appearance of true nucleoli in the late 2-cell stage coincides with the autoradiographic demonstration of nucleolar RNA synthetic activity in the latter. Mintz (1964) reported nucleolar RNA synthesis in 4-cell stage mouse embryos, but Izquierdo and Roblero (1965), using a short pulse of $\mathrm{H}^{3}$-cytidine, could not demonstrate label over the nucleolus of 8-cell mouse morulae. Considering the total gestation period of 16 days in the Syrian hamster, the embryonic development may be accelerated in this species.

The situation of the RNA synthesis in the cleaving stage embryos of mammals may be different from that of the amphibias and other lower animals because of the comparatively scarce amount of the cytoplasmic material of the ovum, and also because of the affluent environment during the embryonic development.

\section{Summary}

Ribonucleic acid synthesis in preimplantation stage embryos of the Syrian hamster was studied cytologically and autoradiographically using whole-mount squash preparations.

Cytologically, the first cleavage chromosomes were large and extended, and the relational coiling was detected. Pronucleus and the early 2-cell stage nucleus were morphologically similar and contained large amount of heteropycnotic blocks, but no ribonucleoprotein was demonstrated either with MayGrünwald-Giemsa staining or with acridine orange. In the late 2-cell stage, however, the morphology of the nucleus differed considerably from that of pronucleus and of the early 2-cell stage. Several ribonucleoprotein-containing nucleoli appeared in each nucleus, and the rest of nuclear area showed coarse chromatin network with scattered heteropycnotic blocks.

Chromosomes, which were extended in the first cleavage, became gradually shorter in the course of preimplantation development. In some metaphases 
in the blastocyst, chromosomes were approximately as compact as those of adult tissues.

Nucleolar RNA synthesis was demonstrated in the late 2-cell stage. Heavy $\mathrm{H}^{3}$-UR incorporation appeared in the nucleoli of blastomeres from the late 2-cell stage to the blastocyst. Chromatin was also active in RNA synthesis. No grains above the background level were observed in the cytoplasm of metaphase and anaphase cells of these embryos.

\section{Acknowledgment}

The author wishes to express his sincere appreciation to Dr. T. C. Hsu for ; his suggestions and criticisms in this study.

\section{References}

Alfert, M. 1950. A cytological study of oogenesis and cleavage in the mouse. J. Cellul. Comp. Physiol. 36: 381-409.

Austin, C. R. 1956. Ovulation, fertilization and early cleavage in the hamster (Mesocricetus auratus). J. Roy. Microscop. Soc. 75: 141-154.

- 1957. Fertilization, early cleavage and associated phenomena in the field vole (Microtus agrestis). J. Anat. (London) 91: 1-11.

- and Bishop, M. W. H. 1959. Differential fluorescence in living rat eggs treated with acridine orange. Exptl Cell Res. 17: 35-43.

Brachet, J., Decroly, M., Ficq, A. and Quertier, J. 1963 . Ribonucleic acid metabolism in unfertilized and fertilized sea-urchin eggs. Biochim. Biophys. Acta 72: 660-662.

Brinster, R. L. 1963. A method for in vitro cultivation of mouse ova from two cell to blastocyst. Exptl Cell Res. 32: 205-208.

Brown, D. D. 1964. RNA synthesis during amphibian development. J. Exptl Zool. 157: 101-113.

Das, C. C., Kaufmann, B. P. and Gay, H. 1964. Histone-protein transition in Drosophila melanogaster. I. Changes during spermatogenesis. Exptl Cell Res. 35: 507-514.

Ficq, A. 1964. Effets de l'actinomycine D de la puromycine sur le métabolisme de l'oocyte en croissance. Etude autoradiographique. Exptl Cell Res. 34: 581-594.

Graves, A. P. 1945. Development of the golden hamster, Cricetus auratus Waterhouse, during the first 9 days. Am. J. Anat. 77: 219-252.

Greenwald, G. S. 1962. Analysis of superovulation in the adult hamster. Endocrinol. 71: 378-389.

Hamilton, W. J., and Samuel, D. M. 1956. The early development of the golden hamster, Cricetus auratus. J. Anat. (Londen) 90: 395-416.

Izquierdo, L. and Roblero, L. 1965. The incorporation of labeled nucleosides by mouse morulae. Experientia 21: 532-533.

Mintz, B. 1962. Experimental study of the developing mammalian eggs: Removal of the zona pellucida. Science 138: 594-595.

- 1964. Synthetic processes and early development in the mammalian egg. J. Exptl Zool. 157: $85-100$.

Orsini, M. W. and Pansky, B. 1952. The natural resistance of the golden hamster to colchicine. Science 115: 88-89.

Sobotta, J. 1895. Die Befruchtung und Furchung des Eies der Maus. Arch. Mikroskop. Anat. Entwick. 45: 15-93.

Thomson, J. L. and Biggers, J. D. 1966. Effect of inhibitors of protein synthesis on the development of perimplantation mouse embryos. Exptl Cell Res. 41: 411-427.

Venable, J. H. 1946. Perimplantation stages in the golden hamster (Cricetus auratus). Anat. Rec. 94: 105-120. 